\title{
ADDITIVE MANUFACTURING OF STEEL AND COPPER USING FUSED LAYER MODELLING: MATERIAL AND PROCESS DEVELOPMENT
}

\author{
J. V. Ecker, K. Dobrezberger, J. Gonzalez-Gutierrez, M Spoerk, Ch. Gierl-Mayer, \\ H. Danninger
}

\begin{abstract}
Fused Layer Modelling (FLM) is one out of several material extrusion (ME) additive manufacturing (AM) methods. FLM usually deals with processing of polymeric materials but can also be used to process metalfilled polymeric systems to produce metallic parts. Using FLM for this purpose helps to save costs since the FLM hardware is cheap compared to e.g. direct metal laser processing hardware, and FLM offers an alternative route to the production of metallic components.

To produce metallic parts by FLM, the methodology is different from direct metal processing technologies, and several processing steps are required: First, filaments consisting of a special polymer-metal composition are produced. The filament is then transformed into shaped parts by using FLM process technology. Subsequently the polymeric binder is removed ("debinding") and finally the metallic powder body is sintered. Depending on the metal powder used, the binder composition, the FLM production parameters and also the debinding and sintering processes must be carefully adapted and optimized.

The focal points of this study are as following:

1. To confirm that metallic parts can be produced by using FLM plus debinding and sintering as an alternative route to direct metal additive manufacturing.

2. Determination of process parameters, depending on the used metal powders (steel and copper) and optimization of each process step.

3. Comparison of the production paths for the different metal powders and their debinding and sintering behavior as well as the final properties of the produced parts.

The results showed that both materials were printable after adjusting the FLM parameters, metallic parts being produced for both metal powder systems. The production method and the sintering process worked out well for both powders. However there are specific challenges in the sintering process that have to be overcome to produce high quality metal parts. This study serves as a fundamental basis for understanding when it comes to the processing of steel and copper powder into metallic parts using FLM processing technology.
\end{abstract}

Keywords: additive manufacturing, $316 \mathrm{~L}$ stainless steel powder, $\mathrm{Cu}$ powder, properties, mcrostructure

Josef Valentin Ecker, Klaus Dobrezberger, Christian Gierl-Mayer, Herbert Danninger: Technische Universität Wien, Getreidemarkt 9/164, 1060 Wien, Austria

Joamin Gonzalez-Gutierrez, Martin Spoerk: Polymer Processing, Montanuniversitaet Leoben, Otto GloeckelStrasse 2, 8700 Leoben, Austria 


\section{INTRODUCTION}

The most common type of material extrusion additive manufacturing (MEAM) is a low-cost process in which a filament is softened, and the soft material is pushed through an orifice, The extrudate is then selectively deposited layer-by-layer to shape a threedimensional object [1]. It has been demonstrated that it is possible to use MEAM for the production of complex-shaped parts not only made out of thermoplastics [1-14] and low melting point metals alloys, but also high-melting-point metallic alloys [1, 15-19], ceramics [20-33], and cermets [34]. In order to obtain metallic, ceramic and cermet parts, highly-filled filaments are used as the feedstock material; the shaped part is then subjected to a process of binder removal and sintering to densify the parts [1], similar to the procedure common in powder injection moulding [2].

Copper parts can be additively manufactured by several methods such as powder bed fusion and binder jetting [35]. Parts obtained by powder bed fusion using electron beam melting tend to have defects caused by the severe dissipation of thermal energy during the melting process, as a consequence of the high thermal conductivity of copper. When using laser-based melting techniques, with copper powders densities of up to $99.9 \%$ can be obtained; however higher power is required $(1000 \mathrm{~W})$ compared to steels $(200 \mathrm{~W})$, due to the lower absorption of the laser radiation and the higher thermal conductivity of copper, which further increases the cost of the AM equipment.

In this investigation we concentrate on the production of steel and copper parts by MEAM.

Additive manufacturing (AM) in general has emerged as a technology for manufacturing parts with complex geometrical features that are not easily obtainable by conventional shaping or subtractive techniques [1]. AM holds the potential to make manufacturing processes more sustainable by improving resource efficiency, extending product life by easy repair, and simplifying supply chains [3-7]. There are numerous variants of AM [8]. For metal parts, powder bed fusion systems and direct energy deposition processes [8] (selective laser melting - SLM, electron beam melting - EBM, and laser-engineered net shaping - LENS) are the preferred methods for manufacturing such complex parts in short production runs $[1,10]$. However, it has been shown that other AM techniques can be used to shape metal parts indirectly [10], namely binder jetting [12] and material extrusion (ME) [8]. Especially ME, also known as fused filament fabrication (FFF) [13-15], fused deposition modeling $\left(\mathrm{FDM}^{\mathrm{TM}}\right)$ [16-18], or fused layer modeling (FLM) [19], henceforth always referred to as FLM, is of considerable interest, since it is the only $\overline{\mathrm{AM}}$ technique that offers a manageable processability of an extensive variety of highlyfilled materials [8, 20-24]. In FLM, a material in semi-liquid state (solid powder in a viscous matrix) is selectively deposited through an orifice according to a pre-defined computer aided design (CAD) model. The material passes through a nozzle, and the printing head or the building platform moves in $\mathrm{x}-\mathrm{y}$ plane in order to form a layer of a part. After the completion of one layer, the printing head moves up or the building platform moves down (along the z-axis) so that the next layer can be deposited on top of the previous one [11]. Next to plunger- and screw-based printing heads, the filament-based design is by far the most popular one, due to the inexpensive acquisition costs and the ease of use of the machines [8].

The most common way to use FLM for metal part production is to follow the process known as Shaping, Debinding, and Sintering (SDS, Fig.) [25, 26]. Therefore, a highly-filled compound consisting of a thermoplastic binder and metallic powder needs to be prepared. After extruding this compound to filaments, parts of complex shape are 
Tab.. It can be seen that stainless steel has the smallest particles, though with wide size distribution, while copper shows also larger particles.
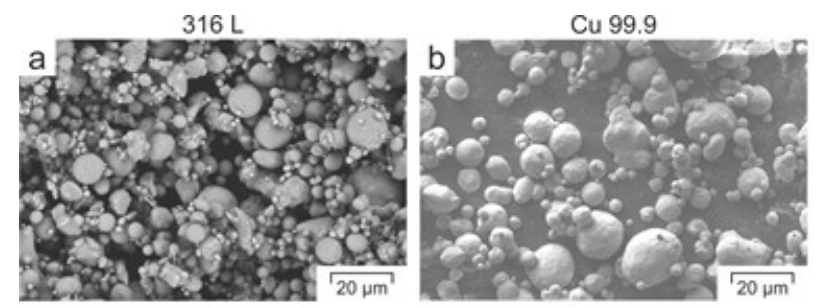

Fig.2. Scanning electron microscopy (SEM) images of the investigated powders $316 \mathrm{~L}$ (a) and $\mathrm{Cu} 99.9$ (b).

Tab.1. Particle size data for metal powders used in feedstocks.

\begin{tabular}{|l|c|c|}
\hline Percentile ranks & 316 L & Cu 99.9 \\
\hline$D_{10}(\mu \mathrm{m})$ & 3.49 & 5.04 \\
\hline$D_{50}(\mu \mathrm{m})$ & 5.53 & 14.55 \\
\hline$D_{90}(\mu \mathrm{m})$ & 8.47 & 29.69 \\
\hline
\end{tabular}

\section{METHODS}

\section{Preparation of feedstocks for processing via Fused Layer Modelling}

\section{Binder preparation}

The binder was prepared by pre-mixing the pellets of the thermoplastic elastomer with those of the grafted polyolefin in solid state. This pre-mixture was then extruded in a single screw extruder (FT-E20T-MP-IS, Dr. Collin GmbH, Germany) equipped with a round die of $1.75 \mathrm{~mm}$ in diameter. The extruded binder was cooled down in a water bath and later granulated in a strand pelletizer (SGS 50-EL, Scheer Reduction Engineering $\mathrm{GmbH}$, Germany). The rotational speed of the screw was set to $70 \mathrm{rpm}$, the temperature profile in the barrel to 180,195 , and $200{ }^{\circ} \mathrm{C}$, and the die temperature to $200{ }^{\circ} \mathrm{C}$.

\section{Feedstock compounding}

All feedstocks were prepared with a constant powder content of $55 \mathrm{vol} \%$ in a corotating twin-screw extruder (ZSE 18 HP-48D, Leistritz Extrusionstechnik GmbH, Germany) with two gravimetric feeding units (DDW-M-DSR28, Brabender Technologie $\mathrm{GmbH}$, Germany). The binder was placed in the first feeding unit, and the metal powder in the second one. The rotational speed of the screw was set to $600 \mathrm{rpm}$, and the temperatures from the feeding zone to the die were $25,180,180,190,200$, and $210^{\circ} \mathrm{C}$. The temperature profile was established by six temperature-controlled heating bands installed along the extruder. The extrudate was transported on an air-cooled conveyor belt (Reduction Engineering Scheer, OH, USA) and pelletized in the strand pelletizer described above. Henceforth, all feedstocks are abbreviated by F-powder, e.g. F-316L for the feedstock filled with the $316 \mathrm{~L}$ stainless steel powder. 


\section{Filament production}

Filaments were produced in the same single screw extruder in which the binder was prepared, equipped with a round die of $1.75 \mathrm{~mm}$ in diameter and $20 \mathrm{~mm}$ in length. However, the extrudate was not water cooled but cooled down by natural convection during the transportation on a conveyor belt (GAL-25, Geppert-Band GmbH, Austria) and a hauloff unit (self-developed). After the haul-off unit, the extruded filament's diameter and ovality was controlled to be $1.75 \pm 0.05 \mathrm{~mm}$ and $<0.1 \mathrm{~mm}$, respectively, by a diameter measurement device and a processor (Sikora Laser 2010T and EcoControl 600, Sikora AG, Germany), and the filaments were stored in spools. The extrusion temperatures and rotational speed were adjusted for each of the feedstocks (Tab.) to accommodate for the different thermal conductivity, flow properties, and mechanical properties of the different feedstock materials. Apart from minor differences in the temperatures, the biggest difference was observed in the rotational speed of the extrusion screw. If the extrudate has enough melt strength and the solid filament has enough tensile strength, the filament can be extruded at a faster rate.

Tab.2. Extrusion parameters for the filament preparation of the two feedstocks investigated.

\begin{tabular}{|l|c|c|}
\hline Extrusion parameters & F-316L & F-Cu99.9 \\
\hline Temperature of the feeding zone $\left({ }^{\circ} \mathrm{C}\right)$ & 180 & 180 \\
\hline Temperature of the compression zone $\left({ }^{\circ} \mathrm{C}\right)$ & 190 & 190 \\
\hline Temperature of the metering zone $\left({ }^{\circ} \mathrm{C}\right)$ & 200 & 195 \\
\hline Temperature of the die $\left({ }^{\circ} \mathrm{C}\right)$ & 200 & 200 \\
\hline Screw rotational speed $(\mathrm{rpm})$ & 39 & 85 \\
\hline
\end{tabular}

\section{Fused Deposition Modeling - production of samples}

Printing trials were performed on an FLM printer X1000 (German RepRap GmbH, Germany), on which the printing head was completely replaced by a self-made dual drive extruder system. For establishing the printing parameters, thin-walled cylinders, each having a wall thickness of $1.3 \mathrm{~mm}$, height of $48 \mathrm{~mm}$, outer diameter of $32 \mathrm{~mm}$, were printed as shown in Fig.2. Subsequently, also other shapes were produced (see below, Chapter 3).
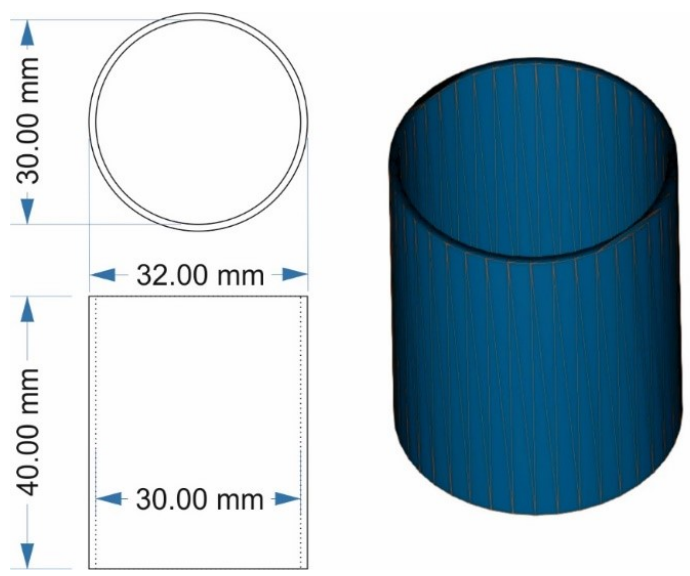

Fig.3. CAD drawing of thin walled cylinders produced by FLM. 
For the $\mathrm{F}-\mathrm{Cu} 99.9$ filament, it was necessary to increase the extrusion temperature to $240{ }^{\circ} \mathrm{C}$, as problems with buckling of the filament occurred at $235^{\circ} \mathrm{C}$ during printing. The problem vanished when printing at $240^{\circ} \mathrm{C}$ due to a reduction of the viscosity of the molten feedstock.

Tab.3. Printing parameters used for the different shaped test samples (cylinders, plates, porous cylinders).

\begin{tabular}{|l|c|c|}
\hline Printing parameters & F-316L & F-Cu99.9 \\
\hline Nozzle diameter $(\mathrm{mm})$ & 0.6 & 0.6 \\
\hline Layer height $(\mathrm{mm})$ & 0.24 & 0.30 \\
\hline Printing speed $(\mathrm{mm} / \mathrm{s})$ & 50 & 30 \\
\hline Extrusion temperature $\left({ }^{\circ} \mathrm{C}\right)$ & 235 & 240 \\
\hline Platform temperature $\left({ }^{\circ} \mathrm{C}\right)$ & 90 & 90 \\
\hline Platform material & Glass & Glass \\
\hline Infill $(\%)$ & 100 & 100 \\
\hline
\end{tabular}

\section{Solvent debinding}

During the debinding process, the organic binder (polymer) is largely removed by dissolving it, only the backbone component remaining. Cyclohexane is used as a solvent at its boiling temperature $\left(81^{\circ} \mathrm{C}\right)$ to secure a constant temperature. The solvent was stirred by means of a magnetic stirrer, whereby the component was placed on a wire mesh to exclusively stir the solvent. The beaker was covered with a watch glass. (Fig.). In order to guarantee successful further sintering steps, debinding using a suitable solvent is essential. Care must be taken to ensure gentle conditions (solvent, temperature) [36]. Drying was carried out in room air at room temperature for several hours, normally overnight.

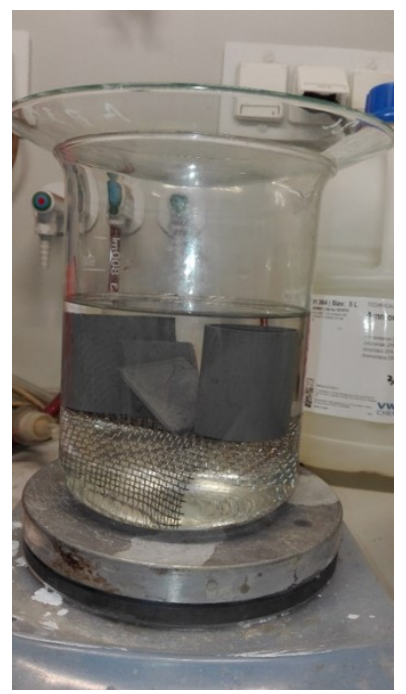

Fig.4. Beaker filled with cyclohexane for debinding. 


\section{Thermal debinding and sintering}

Remaining organic binder residues - the backbone component that ensures sufficient strength of the solvent debinded part - are removed by thermal debinding after the solvent removal process, typically in the early stages of the sintering process, i.e. during heating. Subsequently, sintering takes place, whereby the powder particles form solid metallic bridges, the porosity is reduced and consequently the component shrinks. This results in a solid metallic shape. Sintering requires temperatures of at least around $1000^{\circ} \mathrm{C}$ and has been done in an electrically heated tube furnace (pusher furnace with steel muffle, 1.4841). For $316 \mathrm{~L}$, sintering was performed at $1350^{\circ} \mathrm{C}$ in a Nabertherm furnace with $\mathrm{Al}_{2} \mathrm{O}_{3}$ muffle in dry hydrogen (Air Liquide, Alphagaz, 99.999). Hydrogen humidified by bubbler was used for the sintering of copper. The bubbler was filled with water at room temperature. Sintering processes of various materials have also been thoroughly investigated by Danninger et al. [37-40].

\section{Dilatometry}

Dilatometric measurements were performed using a Netzsch 402C pushrod dilatometer with $\mathrm{Al}_{2} \mathrm{O}_{3}$ measuring system. Those measurements are very important for the determination of dimensional changes as described in [41]. Only $\mathrm{Cu}$ samples were examined in the dilatometer to find the cause of the deformation described below. Dry hydrogen was used as atmosphere.

\section{Mass spectrometry}

Mass spectrometry measurements were carried out using a Netzsch Aeolos QMS 403C with capillary coupling to the dilatometer.

\section{Density measurement and porosity}

The density was measured using the Archimedes principle, where a Mettler Toledo density scale was used. The porosity was calculated from the measured and theoretical density values. Density measurements and porosity are very important techniques to characterise the various properties of sintered materials. [년 43$]$.

\section{Microscopy of sintered samples}

Microscopic examinations were performed using a Zeiss Observer D1 optical microscope. Fine structures of the material can only be determined by microscopic (light and/or electron microscopy) methods. V2A etching agents for steel and Heyn etching agents for $\mathrm{Cu}$ (copper ammonium chloride in $\mathrm{H}_{2} \mathrm{O}$ ) were used as etching agents, and the microstructures were then examined by light microscopy $[\underline{43,44}]$.

\section{Determination of carbon and oxygen content}

The carbon content was measured using a LECO CS230 combustion analyzer, and the measurement of the oxygen content was performed by inert gas fusion with a LECO TC 400. The analysis of carbon and oxygen is a very important task since esp. carbon influences the sintering process. The behavior of carbon on sintering of nonferrous metals such as $\mathrm{Cu}$ and $\mathrm{Al}$ has been the subject of work in the past $[45,46]$. For stainless steels the carbon content should be below $0.02 \%$ to prevent intergranular corrosion. 


\section{RESULTS AND DISCUSSION}

\section{Stainless steel samples}

\section{Samples and specific printing parameters}

The samples E1 and E2 are tubes with approx. $48 \mathrm{~mm}$ height \& $32 \mathrm{~mm}$ outer diameter and $1.3 \mathrm{~mm}$ wall thickness. In contrast, the samples E3 to E5 are plates with a structured surface, approx. $30 \times 30 \mathrm{~mm}^{2}$ and $1.25 \mathrm{~mm}$ thickness. All specimens were produced by the FLM method.
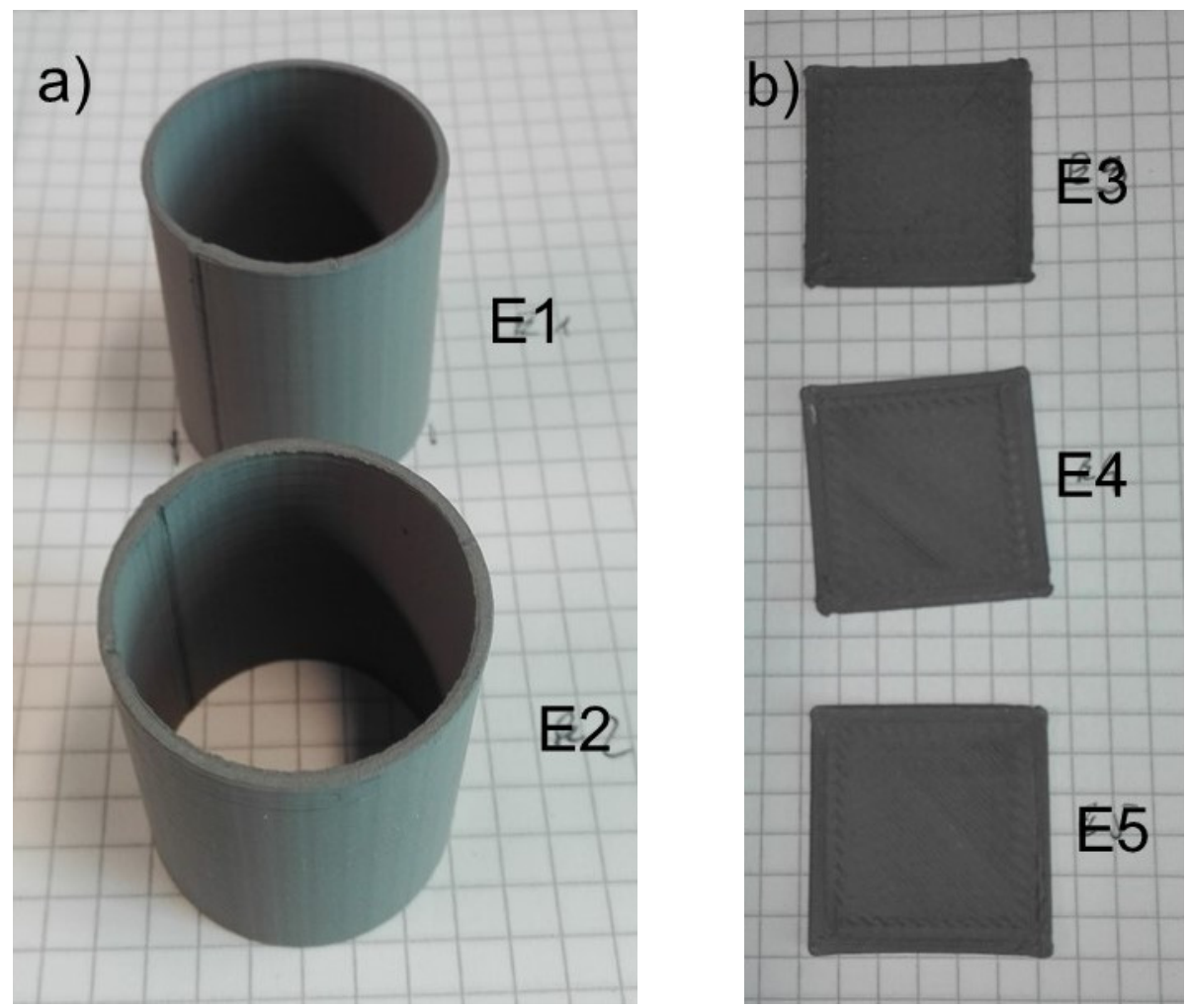

Fig.5. Untreated (as printed) samples E1, E2 (a) and E3, E4 and E5 (b).
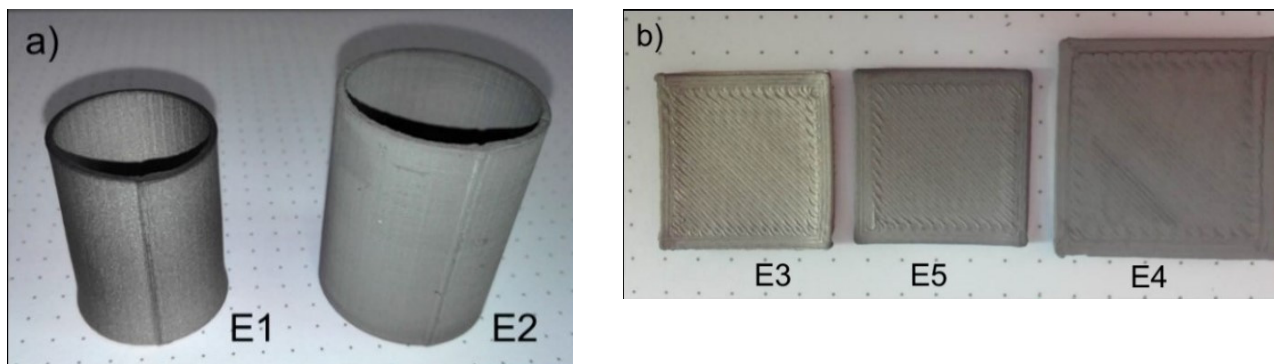

Fig.6. Samples E1 (sintered) and E2 (debinded) (a) and E3 (sintered), E5 (sintered) and E4 (debinded). 
Samples E1, E3 and E5 were used for experiments regarding sintering. E2 and E4 were just debinded with cyclohexane.

\section{Debinding}

Solvent debinding was carried out as described above with magnetic stirring using. cyclohexane. Weight loss was determined by weighing the sample before and after solvent debinding with cyclohexane; data are shown in Tab.. Drying was again carried out in room air at room temperature overnight.

Tab.4. Mass loss during solvent debinding of stainless steel specimens.

\begin{tabular}{|c|c|}
\hline Sample name & Mass loss [\%] \\
\hline E1 & 5.63 \\
\hline E2 & 5.65 \\
\hline E3 & 5.81 \\
\hline E4 & 5.72 \\
\hline E5 & 5.85 \\
\hline
\end{tabular}

\section{Sintering}

The sintering temperature was $1350^{\circ} \mathrm{C}$, and a heating rate of $5 \mathrm{~K} / \mathrm{min}$ was set to heat up to this temperature. It was then kept isothermal for 60 minutes. The samples E1, E3 and E5 were sintered. As stated above the atmosphere was high purity hydrogen.

\section{Density, porosity and $C$ content}

E1 has a relatively low porosity compared to E5. The carbon content was determined in samples E1 and E3 and is very low, which indicates that thermal debinding has been done correctly. The results are shown in Tab.. There are some differences in porosity; However, this parameter is difficult to quantify in the specimen section due to the coarse porosity in the gussets, which at least in laboratory tests may vary slightly between the printing jobs although the conditions for printing the specimens were set identical. The dimensional change of the specimens during sintering could be estimated. For the plate sample E5, the dimensional change is $-15.8 \%$ (dimensions from $30 \mathrm{~mm}$ to $25.25 \mathrm{~mm}$ ). With the cylindrical sample E1, the radial change of the outer diameter is $-15.3 \%$ (dimensions of the outer diameter changed from $31.52 \mathrm{~mm}$ to $25.86 \mathrm{~mm}$ ). The dimensional change during sintering is therefore comparable and similar between the components.

Tab.5. Density, porosity and C content of stainless steel specimens.

\begin{tabular}{|c|c|c|c|}
\hline Sample & Density $\left[\mathrm{g} / \mathrm{cm}^{3}\right]$ & Porosity $[\%]$ & C Content $[\mu \mathrm{g} / \mathrm{g}]$ \\
\hline E1 & 7.39 & 7.64 & $97 \pm 9$ \\
\hline E3 & 7.44 & 6.95 & $107 \pm 11$ \\
\hline E5 & 7.24 & 9.49 & not determined \\
\hline
\end{tabular}

\section{Microstructure}

Microscopic examination of unetched and etched samples was performed at different magnifications. V2A pickle was used as an etchant. The etched structure (Fig.) corresponds to austenitic stainless steel, whereby no carbides are recognizable, which in turn agrees with the very low $\mathrm{C}$ content indicated by LECO analysis. 

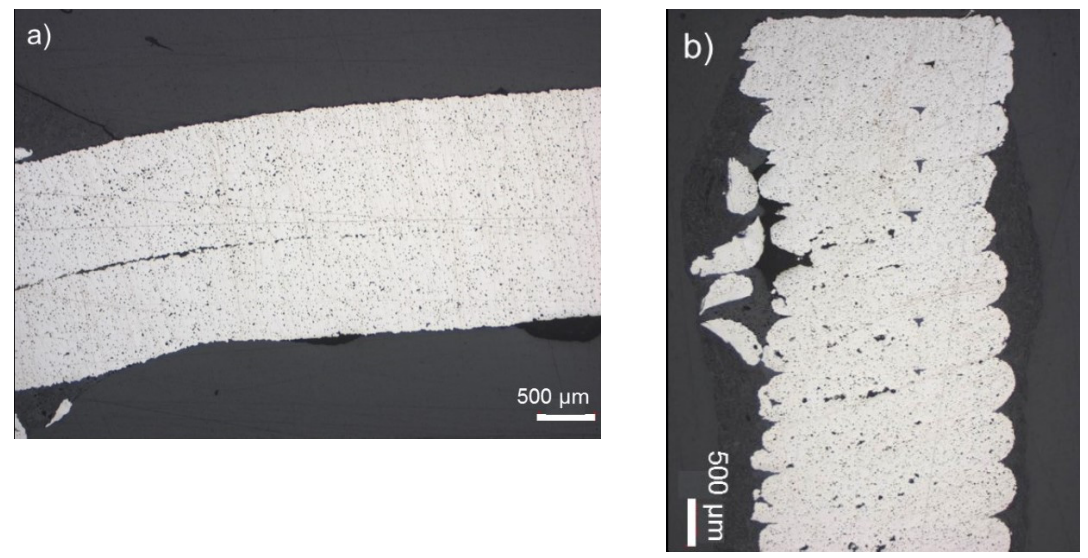

Fig.7. Unetched section of E1 with 50x, parallel (a) and transverse to direction of construction (b).

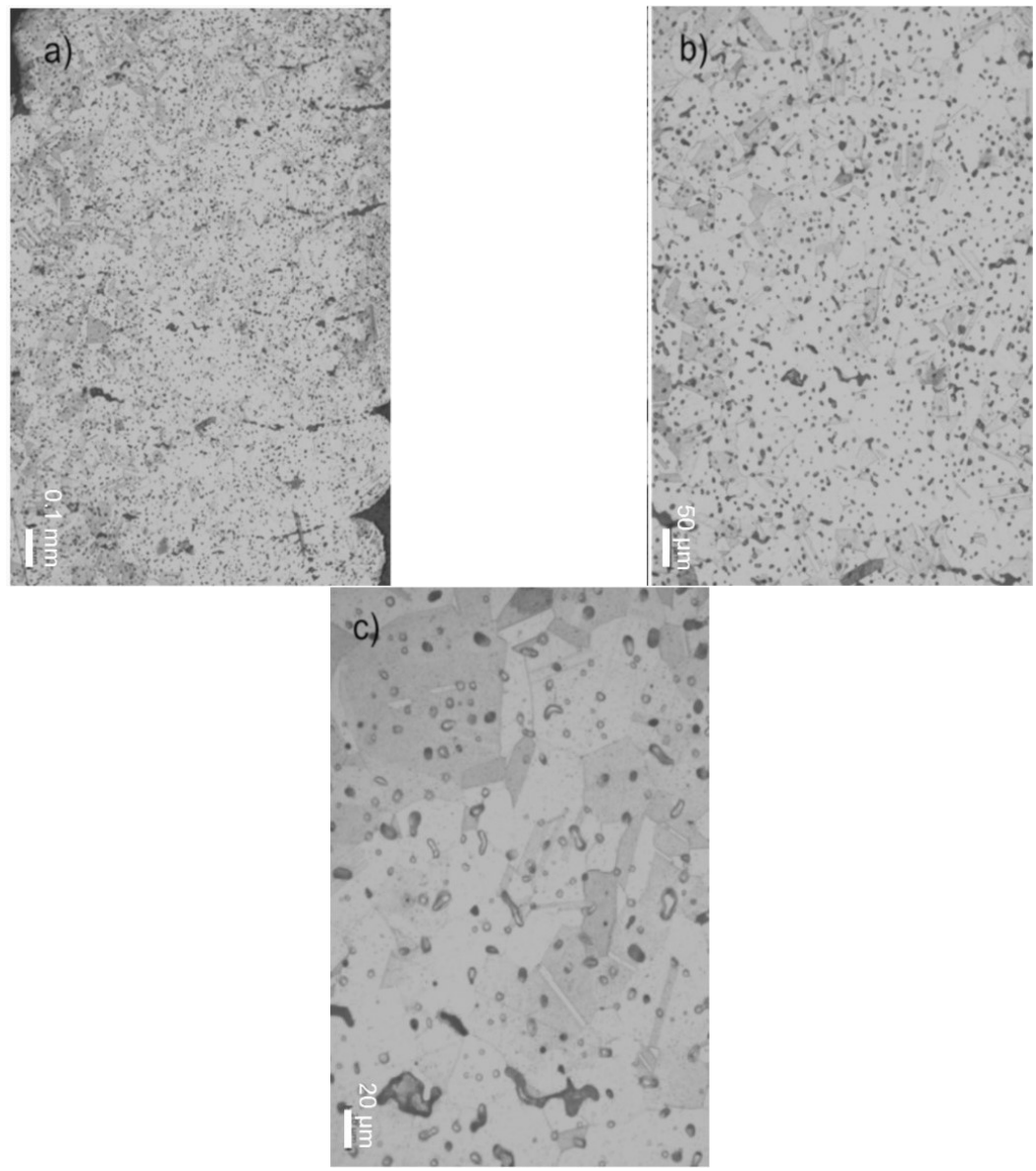

Fig.8. Etched section of sample E1 100x(a), 200x (b) and 500x (c) with grinding transverse to the direction of construction. 
Microscopy shows two types of porosity: fine, evenly distributed pores, which can hardly be avoided in solid state sintering, estimated at approx. $2 \%$, and large pores from the gussets of the printing process, which cannot be reduced or eliminated by sintering and must be avoided during printing. The etched structure conforms to austenitic stainless steel. Once more there are no carbides visible (which are not to be expected at the measured $\mathrm{C}$ content).

\section{Cu-sample}

\section{Samples and specific printing parameters}

Samples of different shapes were prepared by FLM printing. The samples are shown below with their designations.

a)

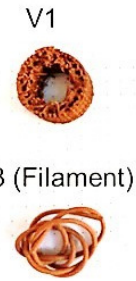

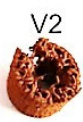

c)

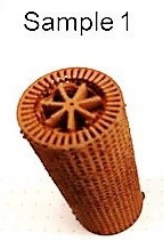

b) Sample 1

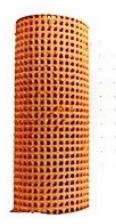

Sample 2

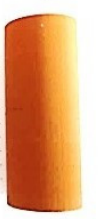

Fig.9. Original samples before debinding. V1, V2 and V3 (a), Sample 1, Sample 2 (b) and

Sample 1, Sample 2 on top (c)

\section{Debinding}

The procedure of debinding was the same as with the steel samples. Mass loss was determined by weighing the sample before and after treatment with cyclohexane and drying in room air at room temperature overnight. Sample V2 was completely unfolded/deformed after the debinding procedure (Fig. a). The mass loss data are shown in the following (Tab.).

Tab.6. Mass loss of different printed $\mathrm{Cu}$ based samples during solvent debinding

\begin{tabular}{|c|c|}
\hline Sample name & Mass loss [\%] \\
\hline V1 & 5.29 \\
\hline V2 & 5.33 \\
\hline V3 (filament) & 5.14 \\
\hline Sample 1 & 5.03 \\
\hline Sample 2 & 4.79 \\
\hline
\end{tabular}

It is obvious that the mass loss of all samples is in the range of about $5 \%$ without significant differences between each other. Thus, the mass loss seems to be independent of the sample shape. 


\section{Sintering}

Sintering of the samples was carried out in the pusher furnace with steel muffle in humid $\mathrm{H}_{2}$ atmosphere, whereby the humidification was carried out with a bubbler at a dew point of $25^{\circ} \mathrm{C}$. The heating rate was $5 \mathrm{~K} / \mathrm{min}$ with a maximum temperature of $1060^{\circ} \mathrm{C}$ held for 60 minutes. The larger sample bodies (Sample 1 and Sample 2) were positioned horizontally in an alumina crucible and thus fed to the sintering process.
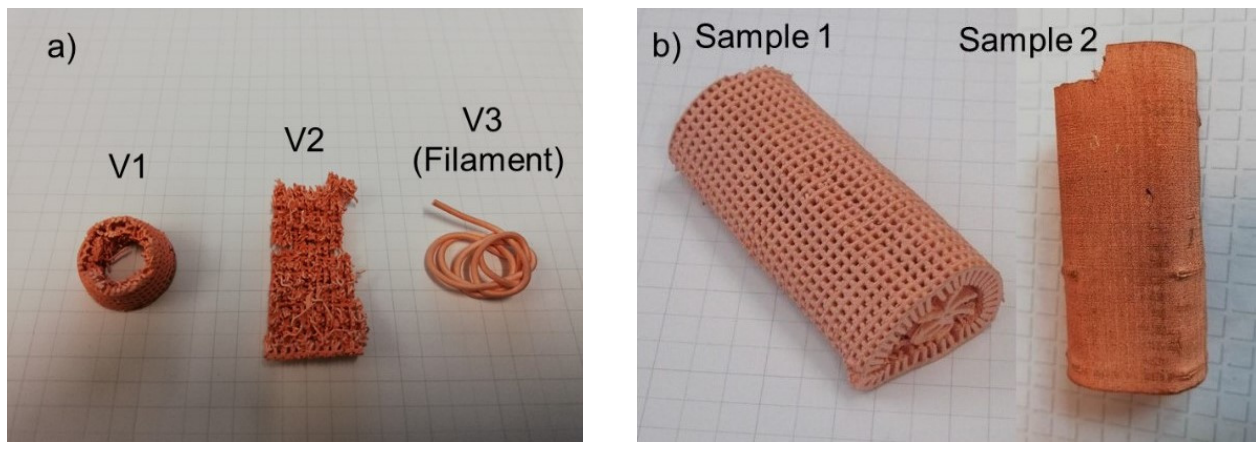

Fig.10. Samples after the sintering process. V1, V2 and V3 a) and Sample 1 and Sample 2 b).

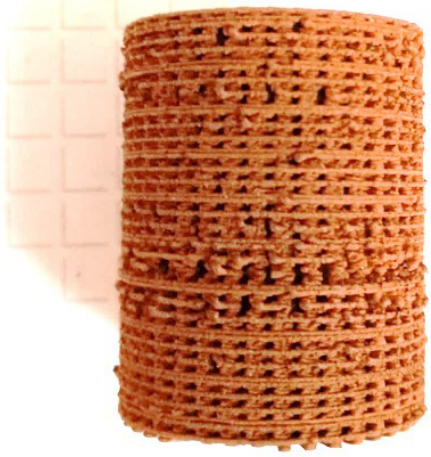

Fig.11. Original sample for test series.

As can be seen, the small specimens V1-V3 more or less retained their shape after sintering, V1 exhibiting some conical distortion. The larger and much heavier specimens Sample 1 and 2, in contrast, were heavily deformed and partially collapsed under their own weight. This collapsing might have occurred during isothermal sintering; however it was also imaginable that melting of the remaining binder, the backbone, had occurred at a low temperature at which hardly any metallic contacts had been formed between the $\mathrm{Cu}$ particles, this melting having resulted in lubrication between these particles and thus in loss of structural rigidity.

In order to potentially overcome this latter problem, two series of tests were carried out during sintering. For this purpose, a $30 \mathrm{~mm}$ high sample similar to Sample 1 was used (Fig.) that had been solvent debinded as described above.

In test series 1, shock debinding was carried out, with the aim of preventing deformation of the sample in the range of $124^{\circ} \mathrm{C}$, because $\mathrm{PE}$ in the backbone starts melting at this temperature. This was to be achieved by producing only gaseous binder burnout 
products which do not lubricate and thus should not cause any deformation of the specimen, i.e. to avoid liquid binder at all. The test run was carried within a sintering process. For this purpose, the furnace was preheated to $400^{\circ} \mathrm{C}$ and the sample was introduced. After isothermal temperature control for 30 minutes, the furnace was then heated to $1050^{\circ} \mathrm{C}$ at 10 $\mathrm{K} / \mathrm{min}$. After the process, the inspection revealed that nevertheless some slight deformation of the components had occurred (Fig.).

In test series 2, an even more severe shock debinding was applied to enhance the effect. The furnace was preheated to $1050^{\circ} \mathrm{C}$ and the sample introduced.
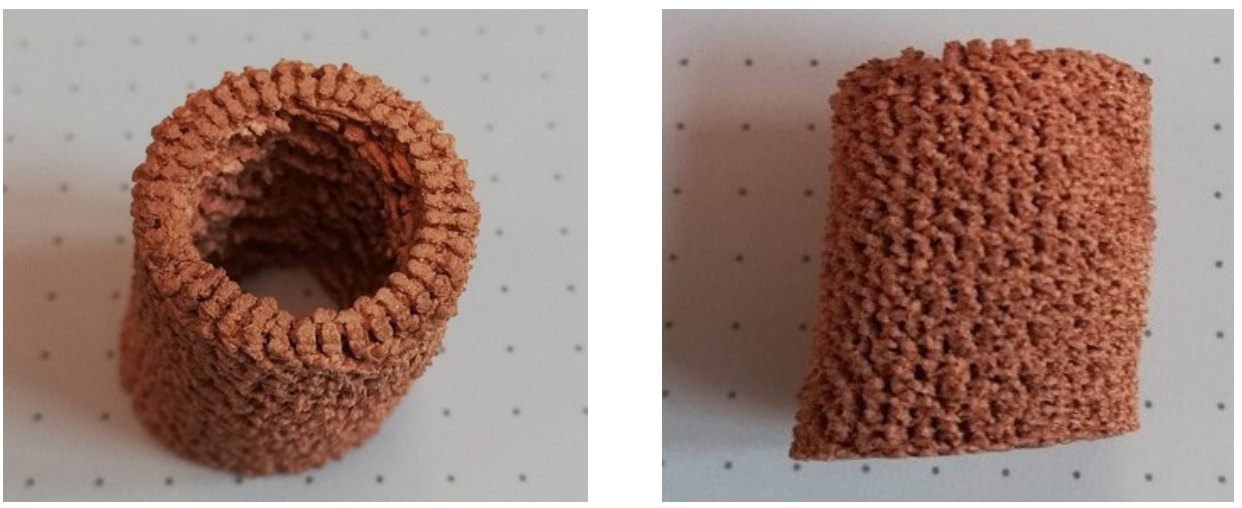

Fig.12. Sintered sample after test series 1.
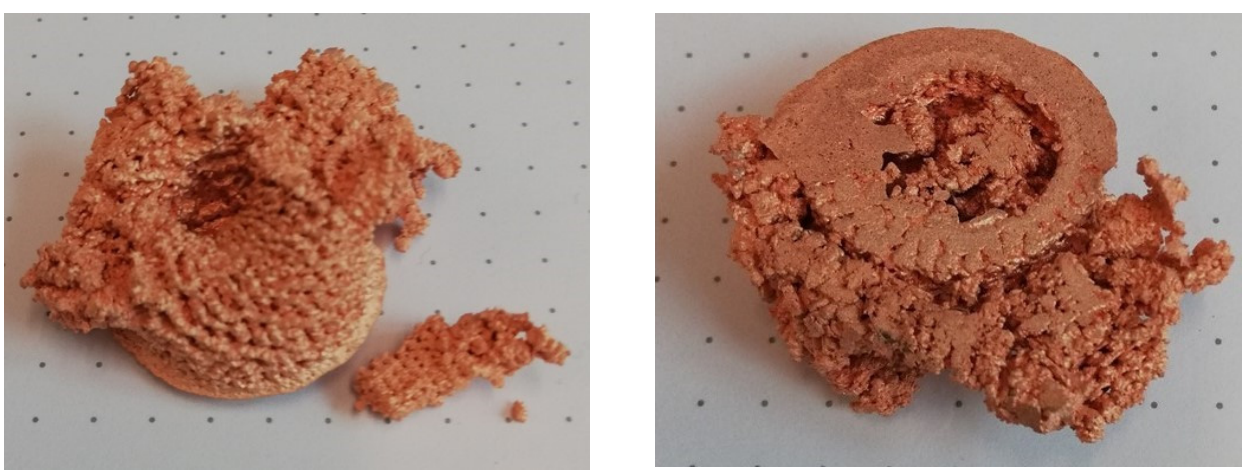

Fig.13. Sintered sample after test series 2.

\section{Dilatometry and mass spectrometry}

Dilatometry tests were performed as follows: $8 \mathrm{~mm}$ thick samples were cut out of sample 2 (see Fig. b). The samples were solvent debinded, dried, placed into the pushrod dilatometer and heated at $5 \mathrm{~K} / \mathrm{min}$ to a maximum temperature of $1030^{\circ} \mathrm{C}$ in flowing hydrogen atmosphere. The dilatometer was coupled with a mass spectrometer to detect any decomposition products of the binder. When the maximum temperature of $1030^{\circ} \mathrm{C}$ was reached, the temperature was maintained for $60 \mathrm{~min}$ (isothermal), and then the dilatometer was cooled down again to room temperature.

A strong shrinkage occurs at approx. $120^{\circ} \mathrm{C}$, as shown in Fig., because PE melts at this temperature. This can lead to a softening of the material at this temperature with resulting loss of strength. A water peak $(\mathrm{m} / \mathrm{z}=18)$ appears at a temperature of $200^{\circ} \mathrm{C}$, indicating the reduction of surface oxides. $\mathrm{CO}(\mathrm{m} / \mathrm{z}=28), \mathrm{CO}_{2}(\mathrm{~m} / \mathrm{z}=44)$ and $\mathrm{CH}_{4}(\mathrm{~m} / \mathrm{z}=$ 
16) are assumed from the detected masses at approximately $400^{\circ} \mathrm{C}$, at which temperature sinter bridges can also be formed. However, atomic oxygen can also occur at $\mathrm{m} / \mathrm{z}=16$ and $\mathrm{N}_{2}$ at $\mathrm{m} / \mathrm{z}=28$, which has the same molecular mass as $\mathrm{CO}$, rendering parallel detection of $\mathrm{O}$ and $\mathrm{CH}_{4}$ as well as $\mathrm{N}_{2}$ and $\mathrm{CO}$ difficult. However, at $400^{\circ} \mathrm{C}$ it is evident that also a peak of $\mathrm{m} / \mathrm{z}=12$ (carbon) and $\mathrm{m} / \mathrm{z}=15$ is visible, which indicates a $\mathrm{CH}_{3}$ fragment from methane and thus supports the theory that indicates the compounds $\mathrm{CO}, \mathrm{CO}_{2}$ and $\mathrm{CH}_{4}$. Thus, it can be assumed that the residual binder is removed at this temperature (Fig.). Dilatometry shows further shrinkage at about $400^{\circ} \mathrm{C}$, which is another indication of the removal of the organic binder and also for the adverse effects exerted on sintering of $\mathrm{Cu}$ by carbon containing compounds.

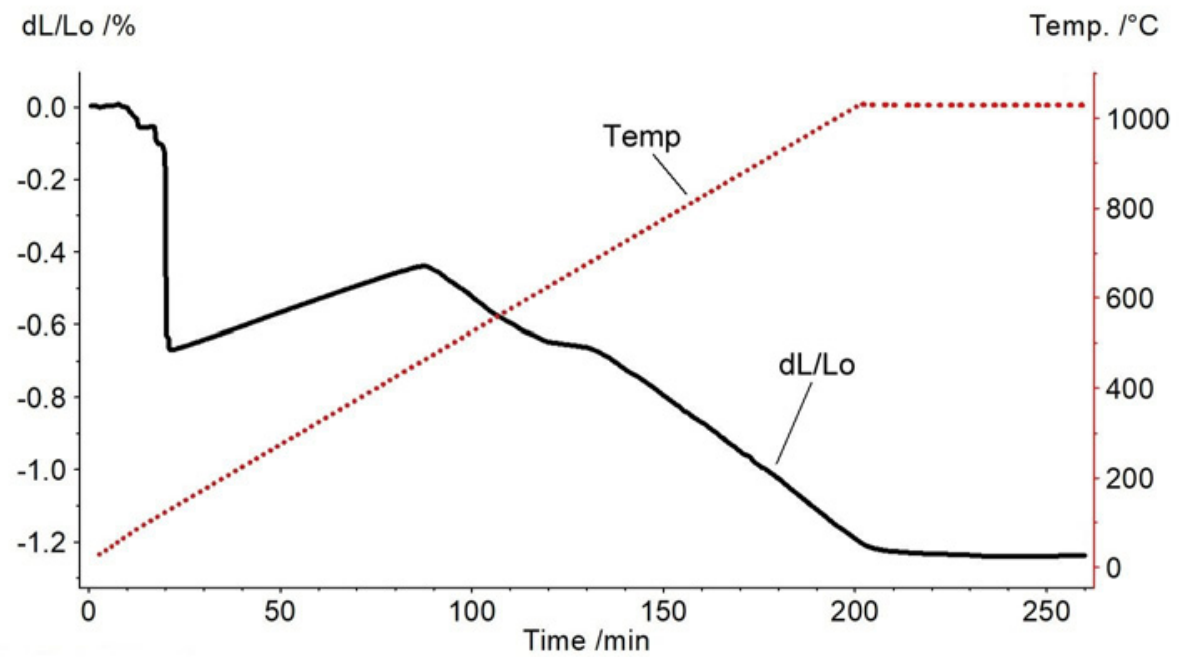

Fig.14. Dilatometry of $\mathrm{Cu}$ sample with a temperature ramp of $5 \mathrm{~K} / \mathrm{min}$ and an isothermal temperature.

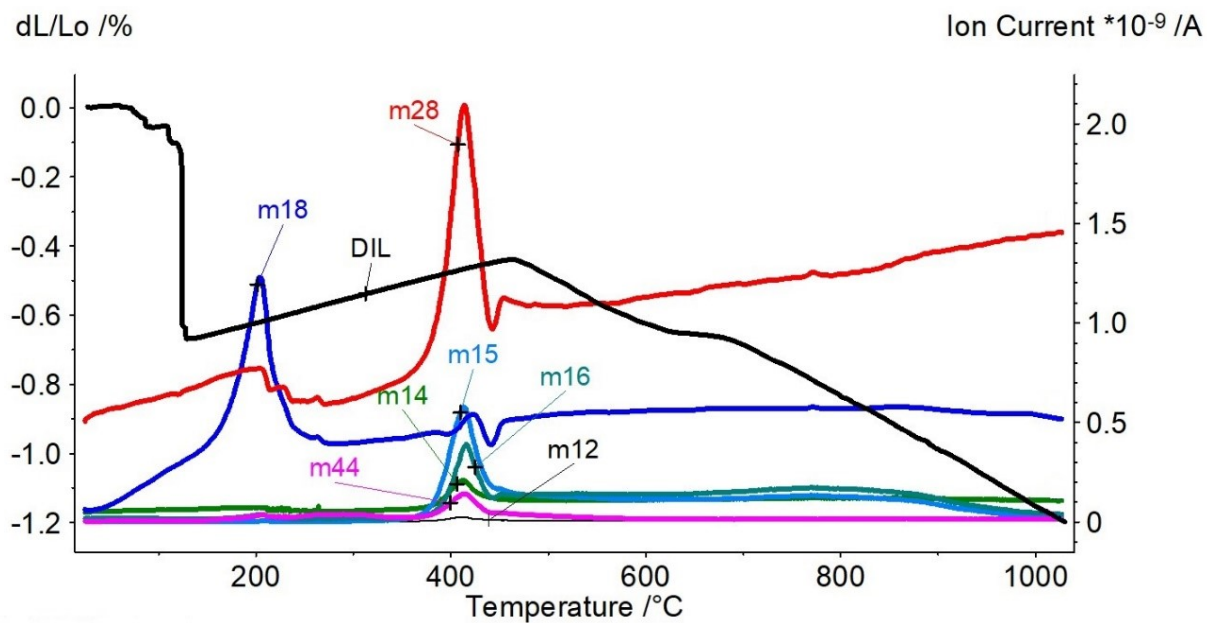

Fig.15. Mass spectrometry graphs of $\mathrm{Cu}$ sample, heating section of the dilatometric run. 


\section{Density, porosity and the amount of carbon and oxygen}

The density measurement was partly not successful, because the wetting of the specimen by the displacement fluid (water) does not work sufficiently well on complex structures, air bubbles remaining and (erroneously) showing too high porosity. The theoretical density of $\mathrm{Cu}$ is about $8.96 \mathrm{~g} / \mathrm{cm} 3$. The porosity was calculated from the theoretical density and the measured one. The results are shown in Tab..

Tab.7. Density and porosity of copper specimens.

\begin{tabular}{|l|l|l|}
\hline Sample & Density $\left[\mathrm{g} / \mathrm{cm}^{3}\right]$ & Porosity [\%] \\
\hline V3 (Filament) & 7.47 & 16,6 \\
\hline Sample 2 & 7.24 & 19,2 \\
\hline
\end{tabular}

The filament V3 shows less porosity than sample 2, which is clear because sample 2 has much more interspaces than the filament that trap air bubbles. Thus, the recorded density of the filament V3 is higher than that of sample 2.

The carbon content and the oxygen content were also measured on the samples V2, V3, Sample and Sample 2. The results are summarized in Tab..

Tab.8. Carbon and oxygen content of copper specimens.

\begin{tabular}{|l|l|l|}
\hline Sample & Carbon $[\mu g / g]$ & Oxygen $[\mu g / g]$ \\
\hline V2 & $50 \pm 16$ & $128 \pm 21$ \\
\hline V3 & $419 \pm 48$ & $230 \pm 17$ \\
\hline Sample 1 & $49 \pm 7$ & $80 \pm 23$ \\
\hline Sample 2 & $29 \pm 9$ & $164 \pm 63$ \\
\hline
\end{tabular}

All samples have a very low carbon and oxygen content, with the sample V3 (filament) having the highest carbon content of $419 \mu \mathrm{g} / \mathrm{g}$. The other samples have a low carbon content (approx. 30 to $50 \mu \mathrm{g} / \mathrm{g}$ ). The oxygen content of all samples is higher than the carbon content, but still relatively low, with sample V3 again having the highest oxygen content $(230 \mu \mathrm{g} / \mathrm{g})$.

\section{Light Microscopy}

Light microscopy images show pores already that are visible in the unetched state and thus are fairly coarse porosity. It is possible that this porosity already originates from inhomogeneities in the starting material and is enhanced by the sintering process, through Ostwald ripening of the pores, i.e. growth of larger pores at the expense of finer ones [47].
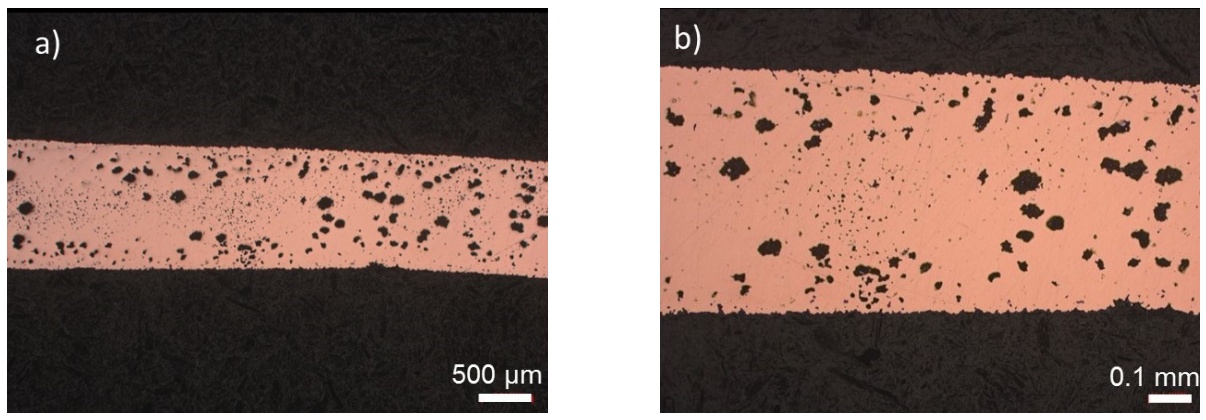

Fig.16. LO micrographs of unetched sintered sample V3 (filament). 25x (a) and 50x (b). 

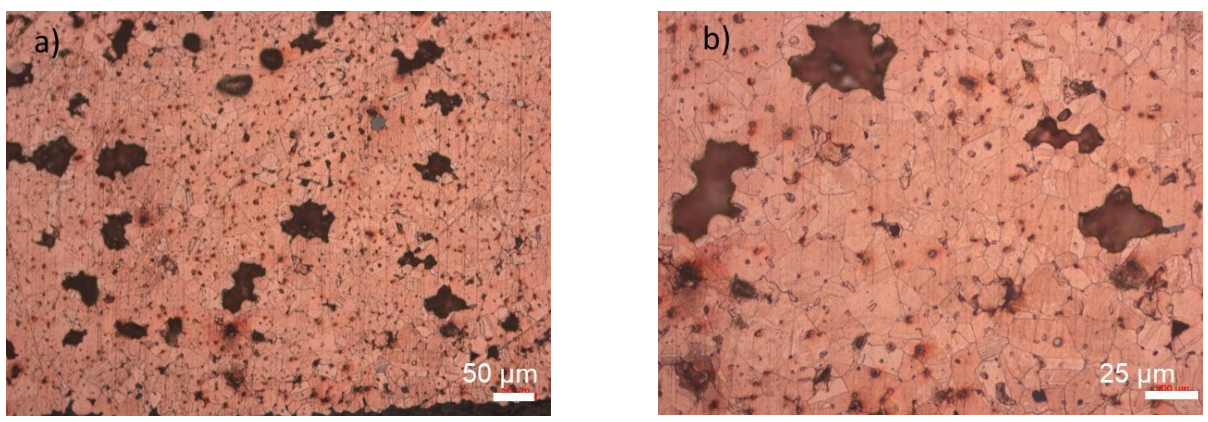

Fig.17. LO micrographs of etched sintered sample V3 (filament), 100x (a) and 200x (b). The etching was carried out by a Heyn-agent.

\section{CONCLUSIONS}

\section{Use of steel feedstock for the manufacturing of components}

Debinding with cyclohexane worked well, although care must be taken with flat components to avoid deformation. The weight loss is approx. $5.7 \%$. The sample E1 stands in a bed of coarse corundum particles during sintering, whereby the shrinkage at the bottom of the tested sample was not the same as on the top. Therefore, one should sinter horizontally or alternatively use a fixed alumina layer (flat, smooth plate). Sintering at $1350^{\circ} \mathrm{C}$ under hydrogen atmosphere resulted in a good densification in any case, and also the carbon content after sintering is very low.

\section{Use of copper feedstock for the production of components}

Debinding has been successful so far, but the parts already become relatively soft at $80^{\circ} \mathrm{C}$. The loss of mass during solvent debinding was approx. $5 \%$ for each sample. In the next step, the samples can be sintered quite well in a humid hydrogen atmosphere. This solves the problem of residual carbon impurities and, consequently, the final $\mathrm{C}$ content and also the oxygen content are very low. The deformation of the specimen takes place relatively early, which has been proved by dilatometry and mass spectrometry. At about $124^{\circ} \mathrm{C}$, the backbone polyethylene already melts, resulting in a loss of structural strength. At $400^{\circ} \mathrm{C}$, the residual organic binder is removed, which is mainly visible by appearance of carbon-containing fragments in the mass spectrometer. The main problem here is the distortion of larger specimens in the early stage of sintering; this should be overcome by using a backbone binder component with significantly higher melting range that remains mechanically stable up to temperatures at which bonds between $\mathrm{Cu}$ particles are already formed. This will be the topic of a subsequent publication.

\section{Comparison of the sintering behaviour and characteristics of the materials}

The comparison of the sintering behaviour of the steel and copper samples shows that both types can be sintered very well. Steel is sintered at markedly higher temperatures $\left(1350^{\circ} \mathrm{C}\right)$ than copper $\left(1060^{\circ} \mathrm{C}\right)$ in hydrogen. The measured density for the steel samples are $7.39 \mathrm{~g} / \mathrm{cm}^{3}$ (E1), $7.44 \mathrm{gm} / \mathrm{cm}^{3}$ (E3) and $7.24 \mathrm{~g} / \mathrm{cm}^{3}$ (theoretical density: $8.00 \mathrm{~g} / \mathrm{cm}^{3}$ ) and the porosity calculated from this is $7.64 \%$ (E1), $6.95 \%$ (E3) and $9.49 \mathrm{~g} / \mathrm{cm}^{3}$. For the copper samples, the measured densities are between 7.2 and $7.5 \mathrm{~g} / \mathrm{cm}^{3}$ (theoretical density: $8.96 \mathrm{~g} / \mathrm{cm}^{3}$ ), with the resulting porosity being between 16 and $19 \%$, which is considerably higher than for the steel samples. However, density measurement is very difficult for the 
complex copper samples studied here due to poor wetting of the structures and trapping of air bubbles. Also the addition of a wetting agent did not result in complete wetting of the copper samples with water, which means that the Archimedes method seems to be hardly suitable for these samples due to the very complex component geometry compared to the steel samples. The density measurement worked best for the copper samples with filament $\mathrm{V} 3$ due to the sample geometry of the filament. The porosity value of $16.6 \%$ of V3 can therefore be considered relatively reliable. The carbon content of all samples is very low and therefore (as well as the oxygen content) does not influence the sintering significantly. The microstructures of the copper samples already showed a high porosity, most probably due to inhomogeneities in the feedstock. In the case of steel, larger pores were found due to the printing process, which must be prevented during printing. However, the fine pores found can hardly be avoided by solid state sintering. In any case, unwelcome reactions between the organic binder and the steel can be suppressed, carbide-free austenitic stainless steel being obtained.

\section{Acknowledgement}

This work was performed as part of the European projects REProMag and CerAMfacturing and the Austria-China bilateral cooperation project FlexiFactory3Dp. Both European projects have received funding from the European Union's Horizon 2020 research and innovation program under Grant Agreements No. 636881 and No. 678503. FlexiFactory3Dp has received funding from the Austrian Research Promotion Agency under the program Production of the Future, Grant Agreement No. 860385.

\section{REFERENCES}

[1] Gonzalez-Gutierrez, J., Cano, S., Schuschnigg, S., Kukla, C., Sapkota, J., Holzer, C.: Materials, vol. 11, 2018, doi:10.3390/ma11050840

[2] German, RM., Bose, A.: Injection molding of metals and ceramics. Princeton NJ : MPIF, 1997

[3] Chacón, JM., Caminero, MA., García-Plaza, E., Núñez, PJ.: Materials \& Design, vol. 124, 2017, p. 143, doi:10.1016/j.matdes.2017.03.065

[4] Heller, BP., Smith, DE., Jack, DA.In: Proceedings of the Solid Freeform Fabrication Symposium. Austin, Texas, 2015

[5] Kuo, C-C., Mao, R-C.: Materials and Manufacturing Processes, vol. 31, 2015, p. 1113, doi:10.1080/10426914.2015.1090594

[6] Ahn, SH., Montero, M., Odell, D., Roundy, S., Wright, PK.: Rapid Prototyping Journal, vol. 8, 2002, p. 248, doi:10.1108/13552540210441166

[7] Alafaghani, A., Qattawi, A., Alrawi, B., Guzman, A.: Procedia Manufacturing, vol. 10, 2017, p. 791, doi:10.1016/j.promfg.2017.07.079

[8] Álvarez, K., Lagos, RF., Aizpun, M.: Ing. Inv., vol. 36, 2016, p. 110, doi:10.15446/ing.investig.v36n3.56610

[9] Bellehumeur, C., Li, L., Sun, Q., Gu, P.: Journal of Manufacturing Processes, vol. 6, 2004, p. 170, doi:10.1016/S1526-6125(04)70071-7

[10] Carneiro, OS., Silva, AF., Gomes, R.: Materials \& Design, vol. 83, 2015, p. 768, doi:10.1016/j.matdes.2015.06.053

[11] Elkins, K., Nordby, H., Janak, C., Gray, RW., Bøhn, HH., Baird, DG. In: Proc. 8th. Solid Freeform Fabrication Symposium. The University of Texas, Austin, August 1113 1997, p. 441

[12] Rahim, TNAT., Abdullah, AM., Akil, H., Mohamad, D., Rajion, ZA.: Express Polym. Lett., vol. 11, 2017, p. 963, doi:10.3144/expresspolymlett.2017.92 
[13] Shojib Hossain, M., Espalin, D., Ramos, J., Perez, M., Wicker, R.: J. Manuf. Sci. Eng., vol. 136, 2014, p. 61002, doi:10.1115/1.4028538

[14] Masood, SH., Song, WQ.: Materials \& Design, vol. 25, 2004, p. 587, doi:10.1016/j.matdes.2004.02.009

[15] Giberti, H., Strano, M., Annoni, M., Yuan, Y., Menon, L., Xu, X.: MATEC Web of Conferences, vol. 43, 2016, p. 3003, doi:10.1051/matecconf/20164303003

[16] Mireles, J., Espalin, D., Roberson, D., Zinniel, B., Medina, F., Wicker, R. In: Proceedings of the Solid Freeform Fabrication Symposium. Solid Freeform Fabrication Symposium. Austin, Texas, 2012, p. 836

[17] Venkataraman, N., Rangarajan, S., Matthewson, MJ., Safari, A., Danforth, SC., Yardimci, A., Guceri, SI. In: Proceedings of the Solid Freeform Fabrication Symposium. Solid Freeform Fabrication Symposium. Austin, Texas, 9-11 August, 1999

[18] Wu, G., Langrana, NA., Rangarajan, S., McCuiston, R., Sadanji, R., Danforth, SC., Safari, A. In: Proceedings of the Solid Freeform Fabrication Symposium. Solid Freeform Fabrication Symposium. Austin, Texas, 9-11 August, 1999, p. 775

[19] Wu, G., Langrana, NA., Sadanji, R., Danforth, S.: Materials \& Design, vol. 23, 2002, p. 97, doi:10.1016/S0261-3069(01)00079-6

[20] Bandyopadhyay, A., Panda, RK., Janas, VF., Agarwala, MK., Danforth, SC., Safari, A.: Journal of the American Ceramic Society, vol. 80, 1997, p. 1366

[21] McNulty, TF., Mohammadi, F., Bandyopadhyay, A., Shanefield, DJ., Danforth, SC., Safari, A.: Rapid Prototyping Journal, vol. 4, 1998, p. 144, doi:10.1108/13552549810239012

[22] Venkataraman, N., Rangarajan, S., Matthewson, MJ., Harper, B., Safari, A., Danforth, SC., Wu, G., Langrana, N., Guceri, SI., Yardimci, A.: Rapid Prototyping Journal, vol. 6, 2000, p. 244, doi:10.1108/13552540010373344

[23] Agarwala, MK., Weeren, R. van, Bandyopadhyay, A., Safari, A., Danforth, SC., Priedeman, WR. In: Proceedings of the Solid Freeform Fabrication Symposium. Solid Freeform Fabrication Symposium. Austin, Texas. Eds. DL. Bourell, et al., 1996

[24] Agarwala, MK., Weeren, R. van, Bandyopadhyay, A., Whalen, PJ., Safari, A., Danforth, SC. In: Proceedings of the Solid Freeform Fabrication Symposium. Solid Freeform Fabrication Symposium. Austin, Texas. Eds. DL. Bourell, et al., 1996

[25] Agarwala, MK., Jamalabad, VR., Langrana, NA., Safari, A., Whalen, PJ., Danforth, SC.: Rapid Prototyping Journal, vol. 2, 1996, p. 4, doi:10.1108/13552549610732034

[26] Allahverdi, M., Danforth, SC., Jafari, MA., Safari, A.: Journal of the European Ceramic Society, vol. 21, 2001, p. 1485, doi:10.1080/00150190108225177

[27] Atisivan, R., Bose, S., Bandyopadhyay, A.: Journal of the American Ceramic Society, vol. 84, 2001, p. 221, doi:10.1111/j.1151-2916.2001.tb00635.x

[28] Bandyopadhyay, A., Das, K., Marusich, J., Onagoruwa, S.: Rapid Prototyping Journal, vol. 12, 2006, p. 121, doi:10.1108/13552540610670690

[29] Iyer, S., McIntosh, J., Bandyopadhyay, A., Langrana, N., Safari, A., Danforth, SC., Clancy, RB., Gasdaska, C., Whalen, PJ.: Int J Applied Ceramic Technology, vol. 5, 2008, p. 127, doi:10.1111/j.1744-7402.2008.02193.x

[30] Jafari, MA., Han, W., Mohammadi, F., Safari, A., Danforth, SC., Langrana, N.: Rapid Prototyping Journal, vol. 6, 2000, p. 161, doi:10.1108/13552540010337047

[31] McNulty, TF., Shanefield, DJ., Danforth, SC., Safari, A.: Journal of the American Ceramic Society, vol. 82, 1999, p. 1757, doi:10.1111/j.1151-2916.1999.tb01996.x

[32] Pistor, CM.: Adv. Eng. Mater., vol. 3, 2001, p. 418, doi:10.1002/15272648(200106)3:6<418:AID-ADEM418>3.0.CO;2-Q 
[33] Rangarajan, S., Qi, G., Venkataraman, N., Safari, A., Danforth, SC.: Journal of the American Ceramic Society, vol. 83, 2000, p. 1663, doi:10.1111/j.11512916.2000.tb01446.x

[34] Lengauer, W., Duretek, I., Schwarz, V., Kukla, C., Kitzmantel, M., Neubauer, E., Lieberwirth, C., Morrison, V. In: Euro PM2018 Proceedings. EURO PM2018 Congress \& Exhibition. Bilbao, Spain, 14. - 18. October. Bellstone : EPMA, 2018 p. 1

[35] Bai, Y., Williams, CB.: Rapid Prototyping Journal, vol. 21, 2015, p. 177, doi:10.1108/RPJ-12-2014-0180

[36] Hwang, KS., Hsieh, YM.: Metall Mater Trans A, vol. 27, 1996, p. 245, doi.org/10.1007/BF02648403

[37] Danninger, H., Frauendienst, G., Streb, K., Ratzi, R.: Dissolution of different graphite grades during sintering of PM steels, 2001, 67, p. 72

[38] Danninger, H., Gierl, C.: Processes in PM steel compacts during the initial stages of sintering, 2001, 67, p. 49

[39] Danninger, H., Gierl, C., Kremel, S., et al.: Degassing and deoxidation processes during sintering of unalloyed and alloeyd pm stells, 2002, 2, p. 125

[40] Azadbeh, M., Danninger, H., Gierl-Mayer, C.: Particle rearrangement during liquid phase sintering of $\mathrm{Cu}-20 \mathrm{Zn}$ and $\mathrm{Cu}-10 \mathrm{Sn}-10 \mathrm{~Pb}$ prepared from prealloyed powder, 2013, 56, p. 2, doi.org/10.1179/0032589913Z.000000000138

[41] Oro Calderon, R. de, Campos, M., Gierl-Mayer, C., Danninger, H., Torralba, JM.: Metallurgical and Materials Transactions A, vol. 46, 2015, p. 1349

[42] Butković, S., Oruč, M., Šarić, E., Mehmedović, M.: Mater Tehnol, vol. 46, 2012, p. 185

[43] Slotwinski, JA., Garboczi, EJ., Hebenstreit, KM.: J Res Natl Inst Stand Technol, vol. 119, 2014, p. 494, doi.org/10.6028/jres.119.019

[44] Hairer, F., Karelova, A.: Etching techniques for the microstructural characterization of complex phase steels by light microscopy, 2008, p. 50

[45] Gierl, C., Danninger, H., Avakemian, A., Synek, J., Sattler, J., Zlatkov, BS., Maat, J., Arzl, A., Neubing, HC.: Powder Injection Moulding International, vol. 6, 2012, no. 4, p. 65

[46] Zlatkov, BS., Griesmayer, E., Loibl, H., Aleksić, OS., Danninger, H., Gierl, C., Lukić, LS.: Science of Sintering, vol. 40, 2008, p. 79, https://doi.org/10.2298/SOS0801077Z

[47] Schatt, W.: Sintervorgänge. Düsseldorf : VDI-Verlag, 1992 